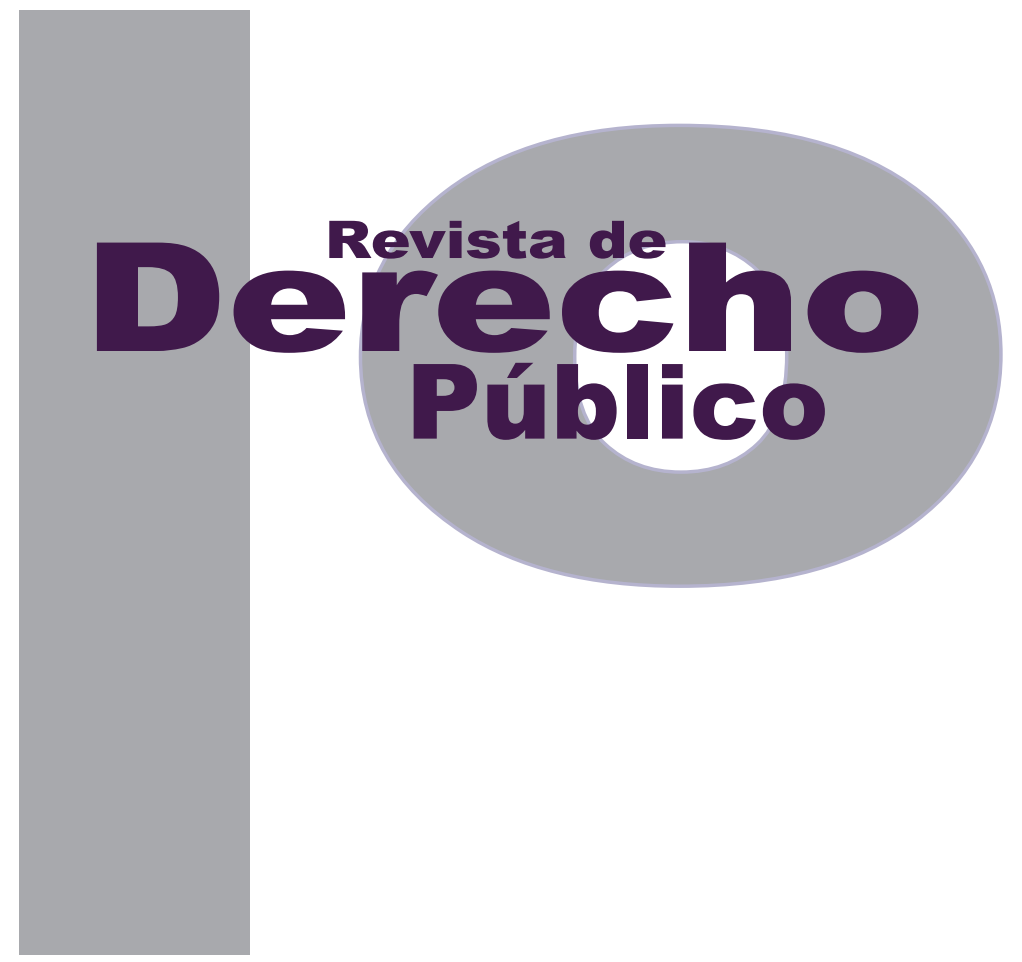

\title{
LA AUTORÍA Y PARTICIPACIÓN EN EL DELITO DE PECULADO
}

\author{
Jorge Arturo Abello Gual
}

Artículo de reflexión

DOI: http://dx.doi.org/10.15425/redepub.35.2015.02

Universidad de los Andes

Facultad de Derecho

Rev. derecho publico No.35

julio - diciembre de 2015. ISSN 1909-7778 


\section{La autoría y participación en el delito de peculado \\ Resumen}

En este trabajo se hace una exposición sobre los criterios necesarios para diferenciar los autores de los partícipes de acuerdo con la ley penal colombiana, y de los efectos que en esta materia producen los elementos especiales del tipo penal de peculado, como son la calidad de servidor público y la relación funcional entre el autor y el bien objeto de protección de este delito.

Palabras clave: autoría y participación, peculado, relación funcional, servidor público.

\section{Perpetration and Participation in the Crime of Embezzlement}

\section{Abstract}

This paper presents a discussion on the criteria needed to differentiate the perpetrators from the participants according to the Colombian criminal law, and the particular effects that this produces within the crime of embezzlement, such as the quality of the public servant and the functional relationship between the perpetrator and that which is being protected from this crime.

Keywords: perpetration and participation, embezzlement, functional relationship, public servant.

\section{A autoria e participação no delito de peculato}

\section{Resumo}

Neste trabalho é feita uma exposição sobre os critérios necessários para diferenciar os autores dos partícipes de acordo com a lei penal colombiana, e dos efeitos que nesta matéria produzem os elementos especiais do tipo penal de peculato, como são a qualidade de servidor público e a relação funcional entre o autor e o bem objeto de proteção deste delito.

Palavras-chave: autoria e participação, peculato, relação funcional, servidor público. 


\title{
La autoría y participación en el delito de peculado*
}

\author{
Jorge Arturo Abello Gual ${ }^{* *}$
}

\section{SUMARIO}

Introducción - I. AUTORES Y PARTÍCIPES EN LA LEY PENAL COLOMBIANA - II. DIFERENCIAS ENTRE AUTORES Y PARTÍCIPES EN LA JURISPRUDENCIA Y EN LA DOCTRINA COLOMBIANA - III. EL RECHAZO DE LA TEORÍA DE LOS DELITOS DE INFRACCIÓN AL DEBER DE ROXIN - IV. ELEMENTOS PARTICULARES DEL DELITO DE PECULADO Y LA AUTORÍA Y PARTICIPACIÓN - A. El servidor público: sujeto activo calificado - B. La relación funcional entre el autor y los bienes protegidos por el delito de peculado - C. La "compleja teoría” de la disponibilidad jurídica y material del bien - V. CONCLUSIONES - Referencias.

Cómo citar este artículo: Abello Gual, J. A. (Diciembre, 2015). La autoría y participación en el delito de peculado. Revista de Derecho Público, 35 . Universidad de los Andes (Colombia).

Este trabajo es parte del proyecto de investigación Estudios de Derecho Penal, financiado por el Politécnico Grancolombiano Institución Universitaria.

** Abogado y especialista en Derecho Penal de la Universidad del Norte. Magíster en Derecho de la Universidad de los Andes. 


\section{Introducción}

En este trabajo se realiza un breve análisis sobre el problema de la autoría y la participación en el delito de peculado, a la luz de la legislación penal colombiana. Sobre el tema propuesto, cabe mencionar que a la dificultad que genera de por sí la discusión en la jurisprudencia y en la doctrina sobre los criterios que se deben tener en cuenta para diferenciar entre autores y partícipes deben agregarse también las particularidades del delito de peculado que hacen más compleja esta labor, como son la calidad de servidor público, y la relación funcional entre el bien y el autor.

El abordaje del problema propuesto se inicia con una breve explicación sobre las formas de autoría y participación en el Código Penal (CP) colombiano, para luego pasar a determinar los criterios que según la jurisprudencia y la doctrina nacional permiten diferenciar entre autores y partícipes, a la luz del derecho penal.

Una vez determinadas las bases para diferenciar entre autores y partícipes, se pasa a explicar las particularidades del delito de peculado, y los efectos que ellas tienen en las figuras de la autoría y participación en dicho delito, como son la calidad de servidor público y el deber funcional que debe existir entre el autor y el bien objeto de la apropiación.

\section{AUTORES Y PARTÍCIPES EN LA LEY PENAL COLOMBIANA}

De acuerdo con el estatuto penal colombiano (art. 29), son autores los que realizan la conducta punible por sí mismos o utilizan a otro como instrumento. También se menciona en el texto citado que son coautores los que, mediando acuerdo común, actúan con división del trabajo criminal, atendiendo que el aporte que realizan al hecho sea de importancia significativa para la comisión de la conducta punible (Velásquez, 2013). Por último, en la norma citada se establece que también será autor:

Quien actúa como miembro u órgano de representación autorizado o de hecho de una persona jurídica, de un ente colectivo sin tal atributo, o de una persona natural cuya representación voluntaria se detente, y realiza la conducta punible, aunque los elementos especiales que fundamentan la penalidad de la figura punible respectiva, no concurran en él, pero sí en la persona o ente colectivo representado.

Por otra parte, el artículo 30 del estatuto penal define como partícipes al determinador y al cómplice. Definiendo al primero como "aquel que determine a otro a realizar la conducta antijurídica"; y al cómplice como aquel "que contribuye a la realización de la conducta antijurídica o preste una ayuda posterior, por concierto previo o concomitante a la misma".

Por último, el mismo artículo trae una figura adicional que es el interviniente, al que define como aquel "que no teniendo las calidades especiales exigidas en el tipo penal concurra en su realización". 


\section{DIFERENCIAS ENTRE AUTORES Y PARTÍCIPES EN LA JURISPRUDENCIA $Y$ EN LA DOCTRINA COLOMBIANA}

De acuerdo con la doctrina, para que exista autor se requiere que la persona a la cual se le esté imputando bajo ese título tenga el dominio del hecho (Jescheck, Weigend y Cardenete, 2002; Velásquez, 2009; Roxin, 2007; Mir Puig, 2010; Ferre, Nuñez y Ramírez, 2010), lo que significa que un sujeto debe tener el poder para adelantar, suspender o aplazar la conducta punible que ha iniciado; en otros términos, es autor el que domina el sí y el cómo del acontecer delictivo. El dominio del hecho es el criterio que permite diferenciar a un autor de un partícipe, en los casos difíciles en los que concurren varias personas en la realización de la conducta punible.

A pesar de lo anterior, es posible encontrar varias posiciones en la doctrina y en la jurisprudencia sobre el tema, porque cuando se busca diferenciar los cómplices de los coautores en determinado caso, la teoría del dominio del hecho sigue siendo una fórmula que permite abrir, en cada caso, una discusión dogmática, conceptual y probatoria. Esto se debe no solo a que la teoría del dominio del hecho es como un elemento normativo del tipo, que adquiere sentido con la decisión judicial, sino que también en la dogmática se plantean diferentes corrientes que hacen variar su contenido y sus efectos (csı Penal, 2 sep. 2009, Y. Ramírez).

Por lo pronto, y ateniéndonos a la ley penal, para que varias personas sean consideradas como coautores de un hecho delictivo se requiere de la existencia de un acuerdo común, de una división de trabajo entre los participantes, y que la entidad del aporte que haga el participante en el hecho sea de tal trascendencia que sin ella no se hubiese podido cometer la conducta punible. En este punto cabe aclarar que para los casos de autoría individual, en la que participan cómplices e instigadores, la teoría que se utiliza para diferenciar entre unos y otros es la teoría del dominio del hecho, pero cuando se trata de casos de coautoría, es decir, cuando varios sujetos fungen en el hecho como coautores, la teoría que permite diferenciar un coautor, de un cómplice o de un determinador, es la teoría del dominio funcional del hecho.

Volviendo a los preceptos del cP, de la entidad del aporte que haga el participante en la conducta punible depende que pueda afirmarse que tenga el dominio funcional del hecho y, por lo tanto, que sea catalogado como coautor. El dominio funcional del hecho implica que el autor no tiene que tener a su cargo la realización directa del verbo rector, como ocurre cuando se actúa con dominio del hecho, sino que, de acuerdo con una división de trabajo antecedida por un acuerdo común, a cada participante se le asigna una labor dirigida a la consumación del hecho delictivo, que puede ser, o no, la realización del verbo rector. Por lo anterior, y siguiendo lo establecido en el artículo 29 del estatuto penal colombiano, de la importancia del aporte que haga el sujeto al hecho delictivo depende, entonces, que se establezca por parte de la autoridad judicial que una persona realizó, en calidad de coautor con otros, un hecho delictivo 
mediando una división de trabajo; o en su defecto, que simplemente contribuyó en calidad de cómplice a la realización de la conducta de otro.

Aunque parece claro, diferenciar un coautor de un cómplice a través de estos criterios no deja de presentar ciertos inconvenientes en la práctica, porque el dominio funcional del hecho también es un criterio abierto, debido a que la alusión a "la importancia del aporte", que no deja de ser abstracta, requiere siempre de la definición judicial en cada caso concreto. Por esta razón, son los jueces y los tribunales los que, a través de la argumentación y de su poder decisorio, terminan definiendo si el aporte de uno de los participantes es importante o no para la realización de la conducta punible, y determinando de esta forma quiénes son coautores o cómplices en cada caso estudiado.

No sobra decir que la Sala Penal de la Corte Suprema de Justicia ha realizado esfuerzos por sentar una definición de coautor, pero aún se encuentran decisiones un poco contradictorias, como por ejemplo la contenida en la decisión del 24 de abril de 2003, donde definió el concepto de coautor de la siguiente manera:

Son aquellos autores materiales o intelectuales que conjuntamente realizan un mismo hecho punible, ya sea porque cada uno de ellos ejecuta simultáneamente con los otros o con inmediata sucesividad idéntica conducta típica, ora porque realizan una misma y compleja operación delictiva con división de trabajo, de tal manera que cada uno de ellos ejecuta una parte diversa de la empresa común (CSJ Penal, 24 abr. 2003, J. A. Gómez).
En esta decisión, por ejemplo, nada se dice de la importancia del aporte, pero sí en cambio se crea un megaconcepto como el de "la compleja operación delictiva con división de trabajo", que termina por incluir en la figura de la coautoría a todos los participantes de la conducta, omitiendo el contenido del artículo 28 del cP que claramente establece que "concurren en la realización de la conducta punible los autores y los partícipes." En consecuencia, por mandato legal, el juez deberá diferenciar entre autores y partícipes muy a pesar de existir una "compleja operación delictiva con división de trabajo".

En otra decisión, la misma Sala de la Corte Suprema explicó así el concepto de coautoría impropia:

Cuando una conducta punible es realizada en forma comunitaria y con división de trabajo por varias personas que la asumen como propia, aunque la intervención de cada una de ellas, tomada en forma separada, no ejecute en forma total el supuesto de hecho contenido en el respectivo tipo penal (CSJ Penal, 6 ago. 2003).

Obsérvese que en ambas decisiones la Sala Penal de la Corte Suprema de Justicia usa como elemento integrador el concepto de división de trabajo, para incluir dentro de la coautoría todas las conductas que se lleven a cabo con esa característica. En las decisiones antes transcritas tampoco se hace referencia a la necesidad de valorar la importancia del aporte; por ello, no queda clara la diferencia entre una conducta realizada por varias personas en división de trabajo, y el aporte que haga una persona a la conducta punible de otra, u otras, en calidad de 
cómplice. En definitiva, en ambas decisiones la Sala Penal de la Corte Suprema de Justicia prácticamente suprime la posible existencia de la figura del cómplice. Además, la referencia al concepto de coautoría impropia no es el más afortunado, pues como se puede evidenciar, ese concepto se basa en la ejecución conjunta de una conducta preacordada; en la asunción voluntaria del hecho como propio (teoría subjetiva de la autoría); y en una ampliación de la figura de la coautoría a hechos que no ejecutan de forma total el precepto penal, y donde no se tiene en cuenta la importancia del aporte (Velásquez, 2013).

A pesar de los pronunciamientos anteriores, la Sala Penal de la Corte Suprema de Justicia en sentencia del 2 de septiembre de 2009 ha incluido dentro del concepto de coautoría, de conformidad con lo establecido en el artículo 29 del $\mathrm{CP}$, la importancia del aporte como uno de los elementos esenciales de la coautoría:

Lo característico de esta forma plural está dado en que los intervinientes despliegan su comportamiento unidos por una comunidad de ánimo, esto es, por un plan común, además, se dividen las tareas y su contribución debe ser relevante durante la fase ejecutiva pues no cabe la posibilidad de ser coautor después de la consumación de la conducta punible.

Desde esta definición, ya no basta el acuerdo común y la ejecución mancomunada del hecho, sino que se explica que el aporte esencial es uno de los elementos que se deben analizar en la figura de la coautoría:
Los coautores por virtud del acuerdo ejercen control en parte y en todo, y lo hacen de manera funcional, es decir, instrumental y el aporte de ellos deberá ser una contribución importante, pues si la ayuda resulta secundaria o accesoria, no podrá hablarse de aquélla forma de intervención sino de complicidad.

Incluso en la citada decisión, se plantea un método lógico para diferenciar entre coautores y cómplices:

En dicha perspectiva, y a fines de que la valoración y atribución de una u otra de las modalidades vistas no dependan del juicio arbitrario o subjetivista de los jueces, se requiere para el instituto visto que la aportación sea esencial, valga decir, deberá entenderse aquella sin la cual el plan acordado no tiene culminación porque al retirarla este se frustra o al compartirlo se lleva a cabo.

(...)

En esa perspectiva teórica y práctica, si al excluirlo del escenario funcional del evento objeto de juzgamiento, este no se produce, la conclusión a la que se puede llegar sin dificultad es la de la existencia de la coautoría, y si al apartarlo aquél de todas formas se consumaría, la valoración a la que se puede arribar es a la presencia de la conducta de complicidad.

Esta decisión de la Sala Penal de la Corte, al contrario de las otras sentencias antes citadas, se encuentra acorde con algunas posiciones doctrinales como por ejemplo las de los profesores Fernando Velásquez (2013), Salazar Marín (2011) y Fernández Carrasquilla (2012), quienes exponen claramente que además del 
acuerdo común y la coejecución de la conducta se requiere que el aporte sea esencial al hecho, de tal manera que sin la concurrencia de dicho aporte el plan delictual no se hubiese llevado a cabo. Incluso, a estas posturas se pueden sumar algunas posiciones jurisprudenciales del comparado sobre la coautoría; por ejemplo, el Tribunal Superior de España define que en los casos de coautoría, el dominio sobre el hecho se convierte en un codominio o dominio funcional, cuando todas las personas que intervienen en el delito controlan el resultado, pues su ocurrencia depende de los aportes que haga cada persona de acuerdo con la división de trabajo (sentencia del 11 de agosto de 2000). Con todo lo anterior, podemos ver que la importancia del aporte termina siendo un factor determinante en la figura de la coautoría, pues permite diferenciar entre coautores y cómplices de una conducta punible.

Por último, y para cerrar el tema de la coautoría, se adiciona un elemento más por parte de la doctrina, y es que los aportes al hecho punible además de ser esenciales deben realizarse en la etapa ejecutiva. Este criterio plantea un límite temporal y material, con el cual se expone que no se puede imputar como coautor a una persona que solo haya participado en los actos preparatorios del hecho delictivo, esto es, un hecho previo a la ejecución y a la consumación del resultado típico, y que por ser preparatorio, además debe ser inidóneo y equívoco. Esta postura es apoyada por Roxin (2007), Díaz y García ConIledo (2009), Velásquez (2013) y Salazar Marín (2011).
Este tema es relevante en los delitos realizados en ejercicio de la función pública de administrar recursos públicos, toda vez, que en estos casos, la participación plural de varias personas es prácticamente necesaria, partiendo de la base que estamos hablando de una agrupación de personas que actúan conjuntamente para cumplir con los fines del Estado y, por ello, se requiere tener claros los elementos esenciales de la figura de coautoría para poder diferenciar entre coautores y partícipes, los cuales de acuerdo con la ley, y con todo lo analizado anteriormente, son los siguientes:

a) Acuerdo común, que determina la intención de las partes, los aportes de cada uno y, por tanto, el límite de la responsabilidad por excesos en el plan.

b) División de trabajo, que establece una asignación de tareas a cada uno de los participantes en el hecho delictivo, que permita evidenciar la coejecución -coordinada- de un acto conjunto desde el punto de vista objetivo, y con esto, que no exista la necesidad de que todos realicen el verbo rector para que sean catalogados como coautores del hecho punible. Igualmente, que exista una relación funcional desde el punto de vista social y normativo que permita relacionar la labor encomendada a cada participante, con la comisión de un hecho delictivo.

c) Que el aporte sea esencial, es decir, que el participante realice una tarea de tal importancia, que se pueda concluir que sin ese aporte la conducta punible no se hubiese podido realizar, y

d) Que el aporte sea realizado en la etapa de ejecución del acto delictivo. 
Para la aplicación de esta teoría del dominio funcional del hecho, y respecto al delito de peculado, en la práctica se requiere tener en cuenta ciertas particularidades de este en el momento de establecer quiénes son autores y quiénes son partícipes en dicho delito. Tales particularidades son: el carácter de servidor público que debe tener el autor, y la relación funcional que debe existir entre el bien y el autor de la conducta. Por esta razón, para que una persona pueda ser coautor del delito de peculado, se requiere:

a) Ser servidor público.

b) Tener a su cargo la administración, tenencia o custodia del bien, en razón o con ocasión de sus funciones.

c) Que exista acuerdo común.

d) Que se presente división de trabajo entre los coejecutores.

e) Que el aporte sea esencial, y

f) Que el aporte sea realizado en la etapa de ejecución del acto delictivo.

\section{EL RECHAZO DE LA TEORÍA DE LOS DELITOS DE INFRACCIÓN AL DEBER DE ROXIN}

Así como en el capítulo anterior se rechazó la teoría de la autoría impropia, por considerarla inadecuada dentro de los cánones legales establecidos en el cP, cuando se adopta la aplicación de la teoría del dominio funcional en el delito de peculado necesariamente habrá que enfrentar- se al objetivo de rechazar la aplicación de la teoría de los delitos de infracción al deber diseñada por Roxin, y utilizada precisamente para delitos como el peculado.

Para comenzar con la discusión, se cita la sentencia del 25 de abril de 2002 en la que la Sala Penal de la Corte Suprema de Justicia aplica la teoría de los delitos de infracción al deber, como se aprecia en los apartes siguientes:

Basta con que alguno de los concurrentes que toman parte en su realización ostente la calidad especial y, por supuesto, infrinja el deber jurídico especial alrededor del cual gira o se fundamenta la protección del bien jurídico, sea cual fuere la posición desde donde se ubique.

(...)

El servidor público o el sujeto calificado en cuya condición y deber jurídico especial se fundamenta la realización objetivo del tipo, no puede actuar como determinador o cómplice, por definición. Su participación se concibe sino a título de autoría en cualquiera de sus modalidades o, en último extremo y residualmente, por comisión por omisión (al tener el deber jurídico de evitar el resultado, lo cual no hace porque concurre a la realización del hecho en connivencia con los demás).

De acuerdo con la postura planteada por la sentencia antes transcrita, parece evidente la aplicación de la teoría de los delitos de infracción al deber en el caso concreto. Esta teoría se fundamenta en la asignación de una posición de garante al funcionario público, y la imputación de responsabilidad penal por la infracción de de- 
beres especiales de protección al bien jurídico tutelados no solo por las acciones sino por las omisiones, convirtiendo de esta forma al funcionario público siempre en un autor, y negándole toda posibilidad de actuar como partícipe, posición que parece retornarnos a los tiempos de la autoría unitaria, hoy prohibida por el mandato legal del artículo 28 del cp, que ordena que en cada caso se haga la diferencia entre autores y partícipes.

Precisamente, uno de los problemas que genera esta posición es que en un delito de peculado que se configura con la acción de apropiación, el aporte que haga un funcionario público a través de un acto omisivo, (que normalmente se puede catalogar como un acto de un cómplice, siempre y cuando no tenga la entidad de dominar funcionalmente el hecho), se convertiría en una autoría por comisión por omisión de un hecho punible, debido a la posición de garante que ostenta el funcionario público, y que se podría configurar con la aplicación del artículo 25 del $\mathrm{CP}$, como también lo ha establecido la Sala Penal de la Corte Suprema en la sentencia del 27 de julio de 2006:

En principio las posiciones de garante se refieren a los bienes jurídicos consignados en el parágrafo del artículo 25 del Código Penal, empero, por la fórmula utilizada respecto de posiciones de garante fundadas en la protección en concreto de un bien jurídico o de la vigilancia de una fuente de riesgo de conformidad con la Carta Política o la Ley, puede extenderse a otros, incluido el de la administración pública (Rad. 25536, A. O. Pérez Pinzón).
Antes de seguir avanzando en el tema, me debo detener un poco en el contenido de la teoría de los delitos de infracción al deber y sus efectos en el delito de peculado. De acuerdo con la teoría de los delitos de infracción al deber, un funcionario público solo puede ser considerado como autor del delito de peculado, ya sea porque realizó una acción que infringe el deber de administración, tenencia o custodia, o en su defecto, no realizó los actos tendientes a que no se produjera un resultado que tenía el deber de evitar, que en este caso es la apropiación de ciertos bienes (Roxin, 2007). Según la teoría de la autoría en los delitos de infracción al deber, toda persona que tenga un deber especial derivado de normas extrapenales, sobre el bien jurídico tutelado, y lo infrinja, responderá como autor. También es necesario anotar que para la configuración de una coautoría en esta teoría, no basta el acuerdo común, la división de trabajo y la entidad del aporte, sino que además es necesario que todos los participantes tengan un deber especial respecto del bien jurídico tutelado que hayan infringido. Igualmente, como lo sostiene Roxin (2007), en los delitos de infracción al deber es indiferente que el autor realice la conducta a través de una acción o a través de una omisión, pues como se dijo anteriormente, “la relación entre el menoscabo del bien jurídico y sujeto del delito solo queda instituida por el quebrantamiento del deber" (Roxin, 2007).

Ahora, partiendo de estos planteamientos, propongo una primera oposición a la aplicación de los efectos de esta teoría, pues favorece la aplicación de la teoría de la autoría unitaria que establece que todo aquel que realice un aporte 
a un hecho delictivo debe ser considerado como autor, teoría que se encuentra proscrita en la legislación colombiana, pues el artículo 28 del cP claramente establece que "concurren en la realización de la conducta punible los autores y los partícipes", por tanto, el juez siempre deberá hacer la diferenciación de autores y de partícipes en toda conducta, por lo cual, de partida, debe rechazarse cualquier planteamiento como el realizado por la Corte, que diga que la participación de un funcionario público en un hecho de corrupción siempre debe tenerse como una autoría. Por ello, considero en principio que la teoría de los delitos de infracción al deber no podría aplicarse en Colombia, si es concebida como una violación a la prohibición de la aplicación de la teoría unitaria de autor.

Otra oposición que debo plantear a la aplicación de la teoría de Roxin (2007) respecto de los delitos de infracción al deber, es que dicha teoría fue diseñada para fundamentar la posición de garante en algunos delitos especiales, y la aplicación de la comisión por omisión en ciertos delitos. En la actualidad la doctrina le ha hecho muchas críticas a esta teoría, las cuales también hay que tener en cuenta para negar su aplicación, incluso Schünemann (2007) confirma su abandono en Alemania. Entre las críticas que se le formulan se encuentra que al fundamentar la responsabilidad del autor en el incumplimiento de deberes extrapenales hace al derecho penal dependiente de normas extrapenales, y con ello se pierde el poder del derecho penal de configuración de los hechos delictivos (Fernández Bautista, 2007; Schünemann, 2007), máxime si se entiende que las normas extrapenales pueden tener contradicciones, incluso, sancionar hechos que el derecho penal no sancionaría, o dejar impunes hechos que sí tendrían relevancia para el derecho penal. Otra crítica que se le hace es que parece olvidar que la tipicidad se configura no con la infracción de deberes extrapenales, que pueden ser sí un indicio de la tipicidad, sino por la imputación objetiva y subjetiva de un hecho típico, es decir, la persona debe haber cometido la conducta descrita en un tipo penal, y no una simple relación causal iniciada por la infracción de un deber (Schünemann, 2007).

Por todo lo anterior, los partidarios de las teorías del dominio objetivo y positivo del hecho (Díaz y García Conlledo, 1991; Roso, 2002) plantean que la teoría de los delitos de infracción al deber de Roxin (2007) genera una forma diferente de imputación en la autoría que no es necesaria, y, además, afirman que no se debe prescindir ni siquiera en los delitos especiales del criterio material del dominio del hecho para diferenciar entre autores y partícipes como, por ejemplo, lo expone en Colombia el profesor Suárez de la siguiente manera:

No es suficiente la infracción de un deber jurídico-público o jurídico-privado para que el especialmente obligado sea autor de infracción de deber, sino que se exige que domine la creación, el no control o el aumento del riesgo objetiva y subjetivamente imputable; en otras palabras, que la infracción del deber especial se integre al dominio del hecho (2007, pág. 494).

De acuerdo con lo anterior, no significa que me oponga a la posibilidad de plantear que un fun- 
cionario público pueda realizar un delito de peculado por comisión por omisión, lo que quiero plantear es que no se puede admitir esta vía aplicando la teoría de los tipos de infracción al deber, que prescinde de la teoría del dominio funcional del hecho, y que por ello impide una mejor manera de diferenciar entre autores y partícipes en el delito de peculado.

En el tema de la comisión por omisión, una de las teorías que combina las posiciones de garante, con el dominio del hecho, es la del dominio sobre la evitabilidad del resultado, desarrollada por el profesor Schünemann (2007), quien considera que el derecho penal puede establecer los criterios necesarios para configurar la responsabilidad por comisión por omisión, sin necesidad de depender de normas extrapenales como lo propone Roxin (2007), y con criterios más concretos que el de la competencia o los roles que plantea Jakobs (1998). Schünemann (2007) expone que para que un individuo sea responsable penalmente por una comisión por omisión debió haber asumido la protección de un bien jurídico o la vigilancia de una fuente de riesgo, y a su vez, debe tener el dominio sobre la evitabilidad del resultado típico. En otras palabras, una persona será autor de una conducta por comisión por omisión, si dentro de su ámbito de dominio pudo prever la producción de un resultado lesivo, y aun así, dejó que el curso causal continuara, produciéndose en últimas el resultado típico, como ocurre en el caso del dueño de un perro, quien viendo que el animal va a atacar a otra persona no hace nada, pudiendo hacer algo para evitarlo (Schünemann, 2007).
Por último, también quiero plantear que la Sala Penal de la Corte Suprema de Justicia al acoger en la sentencia citada al inicio la tesis de los delitos de infracción al deber, optó por una posición que no contempla los criterios materiales que limitan la configuración de la comisión por omisión contenidos en el artículo 25 del cP, pues como se dijo, la mera infracción al deber es un indicio de la tipicidad, pero se requiere de más elementos para configurar la responsabilidad penal en un peculado por comisión por omisión, de conformidad con la legislación penal vigente.

En efecto, la teoría de los delitos de infracción al deber no sería aplicable en Colombia, porque para los delitos especiales por acción, como el delito de peculado, no se requiere de la mera infracción de un deber jurídico especial, sino que, como lo exige el artículo 29 del cP, a su vez es necesario que el autor realice la conducta "por sí mismo", esto es, que se apropie del bien (verbo rector), que tenga el pleno dominio del hecho principal y prohibido; o que en su defecto, realice la conducta junto con otros, mediando acuerdo común y actuando con división de trabajo, de tal forma que sin su aporte no se pueda ejecutar la conducta o la conducta se transforme en otra, por tanto, debe tener el dominio funcional del hecho, que se tendrá de acuerdo con "la importancia del aporte." Por tanto, en Colombia, se acoge para los delitos de acción una concepción dual donde se mezclan las valoraciones normativas y las valoraciones ónticas, afines con las concepciones del dominio del hecho y del dominio funcional del hecho. 
Y en los delitos especiales, realizados por comisión por omisión, de conformidad con lo establecido en el artículo 25 del cp también se adopta una concepción dual. En principio, en la comisión por omisión se requiere que se configure sobre el agente una posición de garante, ya sea para la protección efectiva de un bien jurídico o la vigilancia de una fuente de riesgo de acuerdo con la Constitución o la ley. Y, si bien se exige expresamente el incumplimiento de un deber jurídico de realizar una actuación, también se exige que esa acción evite, o mejor dicho, hubiese impedido con certeza el resultado perteneciente a una descripción típica; para completar, la norma además ordena que el agente tenga la posibilidad de evitarlo, por tanto, no solo se requiere que se infrinja un deber, sino que se requiere la dominabilidad sobre la evitación del hecho, en términos de Schünemann (2007), o como lo explica de otra forma el profesor Velásquez (2013, pág. 427):

Lo definitivo, pues, es que se tenga la posición de garante en la actuación de salvamento ordenada en el caso concreto (capacidad de acción) y que ella, con seguridad de manera concluyente y definitiva, habría impedido la realización del resultado (compromiso de poner en marcha la capacidad de acción.

Con ello, el profesor Velásquez (2013) también comparte que, incluso en la comisión por omisión, por la existencia de un resultado, no solo se tiene que infringir un deber jurídico, sino que además se requiere que la acción desobedecida sea la que impida el resultado. Por ello concluye con certeza que "esa acción debe también ser determinada, esto es, aquella que con certeza, con seguridad, de manera definitiva y sin la necesidad de realizar posteriores acciones intermedias, evite la realización del resultado típico" (Velásquez, 2013, págs. 427, 428).

Lo que ocurre es que como en la comisión por omisión no existe causalidad por existir ausencia de acción, se acude a un concepto de causalidad hipotética para poder equiparar los efectos de una acción a los de una omisión, como lo explica el profesor Velásquez (2013, pág. 430):

Se afirma que la omisión es causa del resultado, si puesta mentalmente en su lugar, la acción esperada, que no es realizada por el omitente, el resultado desaparece con certeza, con seguridad; hay, pues, causalidad hipotética si la acción no realizada hubiera evitado la producción del resultado de manera cierta e indiscutible.

De esta forma, se debe concluir que para configurar la autoría en el derecho penal colombiano, en los delitos realizados por comisión por omisión, no basta solo con la infracción de deberes especiales, sino que se requiere de un dominio sobre la evitabilidad sobre el resultado, donde la conducta omitida por el agente hubiera evitado con certeza el resultado, y por ello, quien tenga el dominio sobre la evitabilidad del resultado deberá ser considerado como autor, y quien no lo tenga, deberá ser considerado partícipe, incluso en los delitos realizados en la modalidad de comisión por omisión (art. 25 cP). 


\section{ELEMENTOS PARTICULARES DEL DELITO DE PECULADO Y LA AUTORÍA \\ Y PARTICIPACIÓN}

\section{A. El servidor público: sujeto activo calificado}

Uno de los elementos particulares del delito de peculado es que es uno de los llamados delitos especiales, es decir, quien lo debe cometer es un sujeto activo calificado, que en este caso requiere ser servidor público. Este concepto de servidor público se encuentra ampliado en el artículo 20 del cP, donde no solo se incluyen a los funcionarios vinculados al Estado por elección popular, por concurso para acceder a la carrera administrativa, por libre nombramiento y remoción, por contrato laboral como en el caso de Ios trabajadores oficiales, sino a los particulares que ejerzan función pública de forma temporal o permanente (Gómez y Gómez, 2008; Peña, 2005; Uribe, 2012). Además de lo anterior, habría que añadirle la interpretación de la Sala Penal de la Corte Suprema de Justicia sobre el tema de las notarías, en la cual estableció que los empleados de estas respondían como servidores públicos:

Si el Notario es el depositario de la función de dar fe pública y si por la complejidad de tareas que debe desempeñar requiere de un equipo de colaboradores, es obvio que estos ejercen una función pública y si en desarrollo de la misma cometen delitos, responden naturalmente como servidores públicos (sentencia del 25 de abril de 2002).
Lo anterior tiene un significado mayúsculo en el entendido que si el Estado delega en un particular una función pública, como lo es la administración de recursos públicos, y para ejercerla se requiere de un trabajo en equipo, todas las personas particulares que hagan parte de ese equipo podrán responder como servidores públicos, y en virtud de ello podrían responder por el delito de peculado, cuando un bien del Estado o de particulares se encuentre bajo su administración, tenencia o custodia, en el ejercicio de una función pública.

Esta posición genera sin duda una problemática grande, pues administrar recursos públicos es considerado una función pública; por esta razón, todo particular que administre recursos públicos sería un funcionario público por asimilación y podría incurrir en el delito de peculado, cuando se apropie de dichos recursos. De esta manera, funcionarios de las empresas contratistas de obras, funcionarios de las empresas prestadoras de salud (EPS), funcionarios de las empresas concesionarias y funcionarios de entidades que ejercen alguna función pública, como las cámaras de comercio y las notarías que recaudan tasas e impuestos, terminarían respondiendo por el delito de peculado cuando se apropien de los recursos públicos que se encuentren bajo su administración, tenencia o custodia.

De acuerdo con la legislación penal colombiana, cuando en una empresa privada que administra recursos públicos se presenta un acto de apropiación de esos recursos, se pueden dar diferentes repuestas partiendo de la concepción de 
autoría y participación desarrollada a partir del el cP, dependiendo de los supuestos de hecho que a continuación paso a analizar.

En los casos en los que los funcionarios de las empresas contratistas de obras, funcionarios de las EPS, funcionarios de las empresas concesionarias y funcionarios de entidades que ejercen alguna función pública, como las cámaras de comercio y las notarías que recaudan tasas e impuestos, se ven involucrados en actos de corrupción que implican la apropiación de recursos públicos, tenemos que partir de la base que es la empresa, en cada caso, y no los funcionarios de ella, la que de conformidad con una relación legal o contractual tiene la función de administrar los recursos públicos. Desde esta perspectiva, es la empresa la que ejerce la función pública y la persona natural que actúa en su nombre no tiene ninguna relación contractual ni legal con el Estado, así que en teoría, es la empresa la que por asimilación se convierte en servidor público y no la persona natural que actúa por ella (Abello, 2010a, 2015). ${ }^{1}$

Para estos casos particulares, el cp en el artículo 29 consagra la figura denominada el actuar por otro, que permite transferir las calidades especiales contempladas en el tipo penal, de las empresas a las personas que la representan:

Sobre este tema había planteado en un trabajo anterior, que debido al criterio de especialidad, en los casos de los administradores de las EPS debía aplicarse el delito de abuso de confianza agravado y no el delito de peculado. Sin embargo, la posibilidad de aplicar el delito de peculado solo a los representantes legales a través de la figura del actuar por otro, parece ser una postura razonable y política criminalmente viable para la protección de los recursos parafiscales de la salud.
También es autor quien actúa como miembro u órgano de representación autorizado o de hecho de una persona jurídica, de un ente colectivo sin tal atributo, o de una persona natural cuya representación voluntaria se detente, y realiza la conducta punible, aunque los elementos especiales que fundamentan la penalidad de la figura punible respectiva no concurran en él, pero sí en la persona o ente colectivo representado.

De conformidad con esta figura del actuar por otro, solo a los representantes legales o de hecho de la persona jurídica se le podrían transferir las calidades especiales requeridas por el tipo penal, es decir, la calidad de servidor público. En todo caso, se hace necesario hacer la claridad de que el representante de hecho es una ampliación de la figura que incluye a aquellas personas que no teniendo autorización legal o poder legal para representar a la persona jurídica, actúan como tales y son reconocidas como tales al interior de la empresa y por fuera de ella por terceros, lo cual supera las barreras formales de los nombramientos y poderes, y crea un criterio material para asimilar a representantes legales a ciertas personas que quedarían impunes a pesar de que sí actúan como representantes frente a terceros y al interior de la estructura societaria, pero que no cumplen los requisitos formales para ello.

De esta manera, el representante legal o los representantes legales de una empresa privada que administra fondos públicos podrían incurrir en el delito de peculado a través de la figura del actuar por otro, que incluye, como ya se mencionó, a aquellas personas que no siendo formal- 
mente representantes legales actúen como tales al interior de la empresa y frente a terceros. La profesora Patricia Faraldo explica la figura de la siguiente forma:

La integración de otros sujetos distintos del formalmente idóneo en el círculo de autores de los tipos societarios especiales solo se justifica teniendo presente que la conducta de aquellos, a diferencia de la de otros, es materialmente idéntica a la de los sujetos expresamente descritos en el tipo, que son, en los supuestos que nos ocupan, los administradores de hecho o de derecho de una sociedad constituida o en formación (1996, pág. 282).

Debido al criterio de la unidad de imputación, ${ }^{2}$ si un representante de hecho o de derecho se apropia de los recursos públicos, o los desvía para fines diferentes a los señalados por la ley, estaría incurriendo en el delito de peculado, y las personas que en división de trabajo realizan el delito con él, teniendo el dominio funcional del hecho, por no tener el carácter de representantes legales no podrían ser tratados como funcionarios públicos y, por ello, responderían en calidad de intervinientes, figura consagrada en el artículo 30 del cp que establece lo siguiente: "Al interviniente que no teniendo las calidades especiales exigidas en el tipo penal concurra en su realización, se le rebajará la pena en una cuarta parte".

2 "La Sala considera, además, que para que haya lugar a la configuración del tipo especial basta con que alguno de los concurrentes que toman parte en su realización ostente la calidad especial y, por supuesto, infrinja el deber jurídico especial alrededor del cual gira o se fundamenta la protección del bien jurídico, sea cual fuera la posición desde donde se ubique" (CSJ Penal, 25 abr. 2002, C. E. Mejía Escobar).
Las demás personas que puedan intervenir en el acto, como lo serían un instigador o un cómplice, responderían como tales sin la rebaja consagrada para el interviniente, como bien lo estableció la sentencia de la Sala Penal de la Corte Suprema de Justicia del 8 de julio de 2003³ (Figueroa, 2014; Gómez y Gómez, 2008; Uribe, 2012).

Si en la conducta de apropiación de los recursos públicos no interviene un representante legal de hecho o de derecho, el delito que se configuraría sería el del abuso de confianza agravado, si se tratare de un empleado encargado de administrar los recursos a través de un encargo fiduciario, pues este cometería una apropiación sobre bienes muebles, "abusando de funciones discernidas, reconocidas o confiadas por autoridad pública." En este caso se descartaría el peculado, por no presentarse la transferencia de la calidad de servidor público a través de la figura del actuar por otro; por otro lado, según el criterio de especialidad para descartar los concursos de conducta punible, el tipo penal

3 "Por eso, cuando dicha norma utiliza el término intervinientes no lo hace como un símil de partícipes ni como un concepto que congloba a todo aquél que de una u otra forma concurre en la realización de la conducta punible, valga decir determinadores, autores, coautores y cómplices, sino lo hace en un sentido restrictivo de coautor de delito especial sin cualificación, pues el supuesto necesario es que el punible propio solo lo puede ejecutar el sujeto que reúna la condición prevista en el tipo penal, pero como puede suceder que sujetos que no reúnan dicha condición también concurran a la realización del verbo rector, ejecutando la conducta como suya, es decir como autor, es allí donde opera la acepción legal de intervinientes para que así se entiendan realizados los propósitos del legislador en la medida en que, principalmente, se conserva la unidad de imputación, pero además se hace práctica la distinción punitiva que frente a ciertos deberes jurídicos estableció el legislador relacionándolos al interior de una misma figura y no respecto de otras en que esa condición no comporta trascendencia de ninguna clase." (CSJ Penal, 8 jul. 2003, C. A. Gálvez Argote). Esta sentencia ha generado muchas controversias; al respecto: Figueroa, 2014, pp. 93-115; Gómez y Gómez, 2008, pp. 142-162; Uribe García, 2012, pp. 112-117. 
que mejor describe la conducta es el abuso de confianza agravado, y no el peculado. Este supuesto se presentaría en el caso de un jefe o director de algún departamento o dependencia al que se le asigne la facultad de administrar ciertos recursos públicos para efectos internos o externos. En estos casos, el jefe o director no es representante legal de hecho o de derecho de la empresa, y por ello no se le transfiere la calidad de servidor público a través de la figura del actuar por otro, pero como es consciente de que los recursos que administra tienen carácter de públicos no se le puede aplicar el delito de administración desleal, sino el delito de abuso de confianza agravado, que es el tipo más especial que castiga con pena la conducta de quien se apropie de bien mueble ajeno dado a través de un título no traslaticio de dominio (encargo fiduciario), por abusar de funciones discernidas, reconocidas o confiadas por autoridad pública que, en este caso, sería la empresa o el representante legal (Abello, 2010b).

Por otra parte, si la apropiación sobre recursos públicos se cometiere por empleados que no tienen un encargo fiduciario sobre dichos bienes, el delito que se configuraría sería el de hurto agravado por la confianza, y no el abuso de confianza agravado, pues, además de no poderse dar la transferencia de la calidad especial de servidor público por la figura del actuar por otro, el empleado que actúa así no ostenta un título no traslaticio de dominio necesario para el abuso de confianza, y por tanto no realiza una apropiación sino un apoderamiento, con lo que se haría acreedor de una imputación por hurto agravado por la confianza (Abello, 2010b).
Ahora bien, es necesario incluir dentro de lo analizado dos situaciones muy importantes que demarcan también la autoría en el delito de peculado. La primera, establecer que los recursos apropiados, en efecto, sí sean recursos públicos, pues de lo contrario no se podría configurar el delito de peculado en los casos antes planteados. En principio se debe partir de que la mayor parte de empresas a las que se les asigna la administración de recursos públicos también cuentan con recursos privados, como son los aportes de capital que hacen los socios, las utilidades, y las rentas propias de la explotación de otras actividades contenidas en su objeto social, o que producen sus activos fijos. Por esta razón, no puede afirmarse de tajo que la apropiación de dineros o bienes que tenga la empresa son recursos públicos y, por tanto, se configura el delito de peculado. Para empezar, se supone que una empresa, por lo menos desde el punto de vista contable, debe tener claro qué recursos tienen carácter de públicos y cuáles son propios de la empresa, sin embargo, ello no siempre ocurre así. Por ejemplo, en el caso de las EPS, en una época no era fácil diferenciar entre recursos públicos y recursos propios, pues se manejaba el concepto de unidad de caja según el cual tanto los recursos privados como los públicos se administraban en las cuentas generales de la EPs bajo un solo proceso financiero. Solo en los balances mensuales y anuales era posible diferenciar claramente cuánto dinero recibía la EPS del sistema general de salud y cuánto de rentas propias, así como establecer la utilidad generada en cada operación mensual. 
Por esta razón, en las empresas que manejan tanto recursos públicos como recursos privados debe existir una metodología para diferenciar unos de otros. Por regla general se aplica la separación de las cuentas y de los procesos, asignando claramente su administración a personas determinadas, pero como se advirtió anteriormente no siempre se usa la misma metodología. Igualmente, se debe también trazar una metodología que le permita a la empresa determinar claramente cuáles son las utilidades que produce la administración de los recursos públicos, y cuáles las que producen los recursos privados, evitando con ello confusiones. Estas metodologías son importantes porque, en últimas, permiten determinar la naturaleza jurídica de los recursos, y en caso de apropiación o desviación de los recursos públicos poder fácilmente imputar el delito de peculado. De esta manera, si la apropiación llevada a cabo por parte de un representante legal de una empresa que administra fondos parafiscales se ejecuta sobre recursos que no tienen naturaleza de públicos, sino sobre recursos de la propia empresa, el delito aplicable sería una administración desleal y no el peculado (Abello, 2015; Suárez, 2007).

El segundo aspecto que demarca la autoría en el delito de peculado, que tiene que ver mucho con lo anterior, es el conocimiento que debe tener el sujeto activo de que se está apropiando de un recurso público. Ello hace referencia a un conocimiento especial que califica el dolo del autor, pues en el delito de peculado no basta con que la persona sea consciente de que se está apropiando de cosa mueble ajena, sino que es necesario que sea plenamente conscien- te de que esa cosa mueble ajena que se apropia tiene naturaleza jurídica de recurso público. En consecuencia, quien se apropia de unos dineros que administra la empresa, pero no sabe que esos recursos tienen el carácter de públicos porque la empresa no cuenta con una metodología clara de diferenciación de dichos recursos en esa operación, podría incurrir en lo que el cP denomina error sobre un tipo más benigno, que es descrito en la norma de la siguiente forma: "Cuando el agente obre en un error sobre los elementos que posibilitarían un tipo penal más benigno, responderá por la realización del supuesto de hecho privilegiado" (art. 32 num. 10). Por esta vía, el representante de hecho o de derecho de una empresa privada que administre recursos públicos, que no conozca que el dinero de que se está apropiando son recursos públicos, ya no respondería por el delito de peculado, sino por vía del error en el tipo más benigno, podría responder según el caso por administración desleal si tenía dentro de sus funciones la administración de los recursos apropiados, o por hurto agravado por la confianza, si no tenía asignada dicha función. Por esta misma razón, los funcionarios que no siendo administradores de hecho ni de derecho se apropien de dineros sin conocer que son recursos públicos, responderán por el delito de administración desleal, o en su defecto, de hurto agravado por la confianza, según ya se señaló anteriormente, y no de abuso de confianza agravado.

Por último, cabe remarcar que quien no tiene la calidad de representante legal de hecho o de derecho, pero conoce que se está apropiando de recursos públicos que le fueron encargados 
en calidad de administración fiduciaria, debido al conocimiento especial sabe que no realiza el delito de administración desleal en contra de los intereses particulares de los socios sino en contra de recursos del Estado. Por este conocimiento especial, precisamente, el sujeto deberá responder por el tipo penal más especial, esto es, el delito de abuso de confianza agravado, por abusar de funciones discernidas, reconocidas o confiadas por autoridad pública. El problema que deja esta solución, que técnicamente es la más acertada por el principio de especialidad, es que el autor termina siendo beneficiado punitivamente, porque tanto la pena del hurto agravado por la confianza como la de la administración desleal, son más altas que la pena contemplada para el abuso de confianza agravado.

\section{B. La relación funcional entre el autor y los bienes protegidos por el delito de peculado}

Una vez establecidas las variantes que genera la calidad especial de servidor público en la determinación de la autoría y la participación en el delito de peculado, se debe también advertir que de acuerdo con la estructura del delito de peculado contenida en el $\mathrm{CP}$, no todo servidor público podría cometer un delito de peculado al apropiarse de un recurso del Estado, pues además de ostentar dicha calidad, el tipo penal exige una relación funcional entre el autor y el objeto material del delito, esto es, que los bienes del Estado o bienes de particulares en administración, tenencia o custodia se encuentren a cargo del autor del delito (Arboleda y Ruiz, 2013; Fe- rreira, 2006; Pabón, 2011; Uribe, 2012; Gómez y Gómez, 2008).

Para el análisis de este elemento de la relación funcional parto de dos supuestos: el primero tiene que ver con la asignación de la función de administrar, tener o custodiar un bien del Estado o de particulares en ejercicio de dicha función; el segundo se relaciona con la función de disponer de dichos recursos. Hago esta claridad porque para efectos prácticos hay diferencias en estas dos funciones, a pesar de que ambas se encuentran abarcadas por el Diccionario de la lengua española dentro de la acción de administrar (RAE, 2015), que implica tanto las funciones de tenencia como las de disposición, como bien lo explica el profesor Pabón Parra (2011):

Administrar es expresión amplia que indica utilización, empleo o inversión, pero además implica cuidado y custodia; al referirnos a la administración de bienes públicos, tal actividad puede comprender la tenencia directa de los bienes como pueden ser los casos del recaudador, el pagador o el custodio. Pero además el término comprende las facultades de disposición, el contacto jurídico con el bien, como es la situación del ordenador del gasto (pág. 905).

En la función de tenencia o custodia, a un funcionario se le entregan unos elementos de trabajo -un computador, por ejemplo-, a través de un inventario de bienes; si el funcionario se apropia de dichos bienes comete el delito de peculado. En el caso de la función de disposición la situación cambia bastante, porque el funcionario tiene facultades para transferir el dominio de dichos bienes a otras personas, pero se 
encuentra limitado por un procedimiento legal: una asignación presupuestal, una necesidad del servicio, una apropiación presupuestal, y además debe agotar un procedimiento para disponer de dicho bien, en el que deben intervenir varias personas. Por esta razón, cuando se trata de un peculado por apropiación en una acción de disposición de los bienes, la imputación es más compleja, como se verá en la siguiente sección de este artículo.

Comencemos con el primer problema: cómo se debe asignar la función de administración, tenencia o custodia de un bien a un funcionario, para que se le pueda imputar el delito de peculado. La relación funcional desata una discusión sobre el alcance de la expresión "en razón o con ocasión de sus funciones”, que trae el cP, como bien lo explica el profesor Carlos Mario Molina Arrubla (2005, págs. 93-95):

Recordando que una cosa es el cargo y otra muy distinta las funciones propias o inherentes al mismo, hemos de decir que, en sede del peculado, la entrega de tales bienes al servidor público ha de haberse efectuado o por razón de las funciones a este último confiadas o con ocasión de las mismas, pero de ninguna manera por fuera de ellas, porque entonces el hecho cambiaría de denominación. La entrega será por razón de las funciones, cuando es precisamente de resorte del funcionario encargarse de la administración, tenencia o custodia física o jurídica de tales bienes; y será en razón de las funciones, cuando no siendo esa la función propia, esencial o fundamental del servidor, ella se desprende de lo que ordinariamente le compete hacer.

\section{(...)}

Sea que la adscripción del bien al funcionario provenga de la ley o del acto administrativo, como acaba de verse, lo cierto del caso es que no basta con que esa relación sea meramente material, debiendo existir un vínculo jurídico entre tales extremos (agente delictual y objeto material), de tal manera que si el servidor público se apropia de unos bienes sobre los cuales detenta una mera relación de hecho o material, surgida del ejercicio del cargo y no de la función, no se estructurará un hecho punible contra la administración pública sino, a lo máximo, contra el patrimonio económico.

Lo dicho en precedencia denota que en punto a esta situación, han sido presentadas dos tesis extremas: una, que cabría llamar amplia, conforme a la cual bastaría con la simple relación material entre el agente y el objeto, para que la apropiación que verificara el primero sobre el segundo estructurase un peculado, pese a que dicha custodia o administración no hubiese sido adscrita en forma inequívoca por la ley; y la otra, que podríamos denominar estricta o restringida, con sujeción a la cual se postula que no basta con tal relación de hecho, siendo menester la vinculación jurídica entre sujeto y objeto (sujeto activo y objeto material).

De acuerdo con lo explicado por Molina Arrubla (2005), sobre el tema del vínculo funcional exigido en el delito de peculado existen dos posturas. Una que se inclina por la tesis formal según la cual las funciones de administración, tenencia o custodia sobre el bien deben estar asignadas al funcionario por la ley, entendiendo a la ley en sentido amplio, en la cual se incluyen los actos administrativos. Otra que se inclina 
por una tesis material que considera que puede configurarse el peculado sin necesidad de una asignación rígida de la función de administración, tenencia o custodia del bien al funcionario, bastando solo la tenencia material para configurar una relación funcional.

En mi concepto la postura más apropiada para entender el contenido de la relación funcional es la primera, pues el derecho administrativo no admite ni las analogías ni la costumbre para la asignación de competencias a un funcionario público; es más, la misma Constitución en su artículo 122 prohíbe que un funcionario realice funciones que no estén asignadas previamente en la ley. Lo más acertado, partiendo del principio de legalidad que rige en el derecho administrativo y en el derecho penal, es entender la expresión "en razón de sus funciones", que trae el CP en el artículo 395, en el sentido de que el bien se encuentre bajo la administración, tenencia o custodia del funcionario mediante una asignación previa establecida por la ley, entendiendo que la ley comprende el acto de nombramiento, el manual de funciones y el inventario sobre los bienes que se encuentran bajo su cargo. Además de ello, habrá que entender que la expresión "con ocasión de sus funciones" implica que al funcionario a través de un acto de delegación legítimo (un acto administrativo) le asignaron la administración, tenencia o custodia sobre determinados bienes que inicialmente no se encontraban dentro de sus funciones. Así también lo expresa el profesor Cancino (1983, págs. 100-101):

Es cierto que resulta casi imposible que las funciones de todos los empleados que consti- tuyen la administración pública puedan estar detalladas de manera minuciosa por normas o reglamentos; pero lo que sí es cierto es que por mandato constitucional cada empleado oficial debe tener una función fundamental, clara, dentro de su respectivo ámbito, en forma tal que si bien es cierto que no puede establecer una tabla absolutamente detallada de lo que debe hacer, por lo menos sí debe existir claridad tal que permita identificar su función dentro de la administración. De lo contrario sería imposible saber cuándo existe, por ejemplo, "usurpación de funciones", "delitos de responsabilidad", "exceso en los deberes", etc.; y se crearía una verdadera anarquía en la administración, ya que por costumbres más o menos reiteradas se intercambiarían funciones caprichosamente.

$\mathrm{Si}$, en un momento determinado, existe norma que faculta a un superior para asignar ciertas funciones al inferior, ello no implica que ese superior pueda modificar la filosofía de esta funcionalidad y desnaturalizarla o desviarla. Siempre habrá esas posibilidades de extensión, pero, por una parte, la fuente es la misma ley que autoriza y no el caprichoso costumbrismo, y por la otra, esa autorización está limitada por un principio de respeto hacia la original naturaleza de la función.

Por su parte, Molina Arrubla (2005) considera que la disponibilidad jurídica debe darse de dos formas: inmediata, que es cuando el sujeto activo tiene materialmente los bienes, y mediata cuando el sujeto activo tiene el poder de ordenar realizar actos de disposición a quienes tienen la administración material de los bienes. Menciona también que esa disponibilidad jurídica se debe limitar a los deberes específicos del cargo, 
y evitar acudir a los deberes generales que terminarían por producir resultados injustos:

En síntesis, es suficiente la capacidad para disponer de los bienes, así sea por interpuesta persona, siempre y cuando ello aparezca como una consecuencia directa de la función jurídica desempeñada por el agente delictual, para que pueda predicarse la disponibilidad de los bienes por parte suya. Evidentemente, lo que se incrimina es el fraude cometido por razón de los deberes propios y no el fraude por razón de una función pública general, como que, por ejemplo se correría el peligro, con base en el numeral 20 del artículo 189 de la Constitución Nacional, según el cual es función y deber del Presidente de la República, "velar por la estricta recaudación y administración de las rentas y caudales públicos y decretar su inversión de acuerdo a las leyes", el que se hiciere responsable, de todas las acciones $u$ omisiones punibles en el campo de los delitos contra el Patrimonio Público, patentizadas por parte de sus subalternos quienes sí tienen la disponibilidad material, inmediata, sobre tales bienes (Molina Arrubla, 2005, pág. 97).

De esta forma, debe entenderse que cometen el delito de peculado solo aquellos funcionarios que previamente tengan asignados, a través de la ley o actos administrativos concretos, la administración, tenencia o custodia de determinados bienes del Estado o de particulares, o que no teniéndolos inicialmente les fueron asignados con ocasión de sus funciones, esto es, a través de un acto administrativo de delegación legítimo por un superior o una autoridad competente, que tuviera inicialmente la titularidad de dicha función. De no presentarse alguno de estos dos casos, se podría afirmar que el funcionario no estaría cometiendo un delito de peculado, sino un delito contra el patrimonio económico.

Los efectos de todo lo anteriormente reseñado en la autoría y participación, es que solo aquel funcionario al que se le haya asignado directamente por la ley o por un acto administrativo, o indirectamente a través de un acto de delegación legítimo, la administración, tenencia o custodia sobre un bien del Estado, podrá ser autor del delito de peculado; los demás que participen con el autor, que no tengan dicha relación funcional con los bienes, incluso siendo funcionarios públicos, deberán ser tratados como intervinientes si tienen el dominio funcional sobre el hecho, y los que no tengan tal dominio deberán ser tratados como cómplices o determinadores, según el caso.

\section{La "compleja teoría" de la disponibilidad jurídica y material del bien}

En el caso de la función de disposición de los bienes del Estado, que son aquellos en los que un funcionario público tiene la función de ordenador del gasto, esto es, la posibilidad de transferir los recursos públicos a otras personas, previo el cumplimiento del procedimiento y unos requisitos legales, la Sala Penal de la Corte Suprema de Justicia, en sentencia del 23 de septiembre de 2003, ha explicado que en tales casos la imputación del delito de peculado se extiende a todos los funcionarios que participan en la elaboración de dicho acto complejo: 
La teoría compleja de la disponibilidad jurídica sobre el presupuesto aceptada pacíficamente por la doctrina y la jurisprudencia, incluida la de esta Sala, implica que no solo el ordenador del gasto puede ser autor de peculado por apropiación, sino también el titular de la iniciativa en materia de gasto, y otros funcionarios como por ejemplo el auditor, el revisor fiscal, el pagador, siempre que hubieren tenido el deber de actuar en algún eslabón del acto complejo y que hubiesen sustituido por su voluntad dolosa los postulados de la Ley, decreto, resolución, reglamento, manual de funciones, procedimientos institucionalizados no escritos, etc., que contemplen tal deber.

No se debe confundir la disponibilidad material o física sobre el presupuesto (...) posibilidad que puede recaer en un funcionario exclusivo y determinado, como el ordenador del gasto y el almacenista, entre otros, con la disponibilidad jurídica del mismo, pues este concepto amplio no solo involucra a los anteriores sino que se extiende a todos aquellos que deben intervenir de manera imprescindible para que el compromiso de la erogación nazca a la vida jurídica.

La sentencia antes transcrita genera un problema, pues en principio enumera una cantidad de funcionarios que podrían responder por un delito de peculado, inicialmente bajo la condición de que participen en el acto complejo que produce la disposición de un recurso público, sin embargo, en cada caso concreto se debe hacer un análisis sobre el procedimiento que se debe seguir para realizar un acto de disposición de recursos públicos, y los funcionarios que deben intervenir para que dicho acto surta sus efectos jurídicos.
Ahora bien, incluso con esta sentencia de la Sala Penal de la Corte Suprema se deben revalidar los criterios ya señalados de la legislación y la doctrina colombiana, para diferenciar entre autores y partícipes en el delito de peculado. Por tanto, no es cierto como lo plantea la sentencia antes citada, que todo aquel que participe en el acto administrativo complejo que dispone de un recurso público debe responder como coautor, pues esa afirmación no se compadece con los criterios que ya hemos trabajado y que debemos utilizar para diferenciar entre autores y partícipes.

Tomemos un ejemplo para aplicar los criterios expuestos, y así desvirtuar la afirmación de la Corte Suprema. Una entidad pública requiere contratar a una persona a través de un contrato de prestación de servicios; para ello debe haber una solicitud de la necesidad para contratar; posteriormente se debe hacer una solicitud a tesorería sobre la disponibilidad presupuestal que confirme que la entidad sí tiene el presupuesto para contratar; luego debe hacerse la apropiación presupuestal por parte de tesorería, para que los recursos queden comprometidos al cumplimiento de esa obligación; por su parte, recursos humanos debe verificar que el aspirante cumpla con los requisitos para el cargo; una vez hecho esto, el departamento de jurídica debe elaborar el contrato para que, por último, lo firmen el director de la entidad y el aspirante. En el mismo contrato se asigna un interventor para que vigile y controle el cumplimiento del trabajo del contratista, de forma que una vez el contratista presente el informe de gestión es el interventor quien debe aprobarlo; luego de 
ello el contratista deberá pasar a tesorería una cuenta de cobro junto con otros soportes, como el pago de seguridad social. Tesorería estudia si la cuenta de cobro reúne todos los requisitos para ser pagada, y de ser así la incluye dentro del plan de pagos que le pasa mes a mes al director de la entidad para su aprobación. El director, que tiene la función de ordenador del gasto, revisa y aprueba el plan de pagos; los recursos los gira tesorería de las cuentas de la entidad, a través de cheques o giros electrónicos.

En el caso planteado existen muchas variantes para aplicar un delito de peculado. Por ejemplo, si el contratista no cumple con su trabajo o lo realiza de forma defectuosa, pero se pone de acuerdo con el interventor para que este apruebe el informe de gestión de todas formas, una vez aprobado pasa la cuenta de cobro respectiva, que es posteriormente pagada. La respuesta penal al caso anterior debe darse de la siguiente manera: el contratista, de conformidad con la Ley 80 , se asimila a un servidor público, razón por la cual se apropiaría de recursos públicos, y el interventor, que también es un servidor público, estaría permitiendo que otro se apropie de tales recursos. El problema con esto es que el contratista no tiene bajo su responsabilidad la administración, custodia o tenencia de los recursos públicos de los que se está apropiando, pero con su conducta busca recibir el pago de un trabajo que no ha realizado. Sin embargo, sí tiene un deber funcional sobre los recursos que está cobrando: actuar legalmente y cumplir con sus obligaciones contractuales, de tal forma que con su conducta no genere una apropiación indebida de recursos públicos; este deber se concreta en no cobrar hasta haber cumplido las condiciones establecidas en el contrato. De esta manera, en el caso del contratista, el deber de no cobrar cuando no se cumplan las condiciones del contrato se asimilaría a la del ordenador del gasto, de no pagar hasta que no se cumplan las condiciones del contrato, concretando así un deber de administración y custodia sobre los recursos públicos que debe cobrar. El interventor, por su parte, tiene una función de control y vigilancia sobre el pago de un trabajo, y la de evitar la apropiación de los recursos por parte del contratista; su deber, entonces, se concreta en confirmar que el contratista cumplió con las condiciones contractuales, que es la condición principal para proceder al pago. Así las cosas, el interventor tendría un deber de custodia sobre el pago de los recursos públicos, de conformidad con las obligaciones contractuales. En consecuencia, desde el punto de vista de la imputación objetiva, ambos crean un riesgo jurídicamente desaprobado, pues uno infringe sus obligaciones contractuales y el otro incumple sus obligaciones de control y vigilancia sobre el cumplimiento de dichas obligaciones, que posteriormente se concretan en el resultado de apropiación ilícita de los recursos públicos.

De esta forma, se plantearía la coautoría de un delito de peculado entre el interventor y el contratista, pues para que se configure la apropiación se requiere que el contratista presente el informe de gestión falso, que el interventor lo apruebe, y que luego el contratista presente la cuenta de cobro con todos los soportes, para que la tesorería lo incluya dentro del plan de pagos que le va a presentar al director de la en- 
tidad. En el caso planteado se puede verificar que entre el contratista y el interventor existió un acuerdo previo, una división de trabajo, y que debido a la importancia de los aportes que hicieron ambos al hecho punible, los dos tienen el dominio funcional del hecho; que los aportes fueron realizados en la etapa ejecutiva del acto; que ni el director que aprueba el pago ni el tesorero que gira posteriormente los recursos podrían responder por el delito de peculado doloso, porque a pesar de haber intervenido en el acto complejo de la disposición no tenían ni el conocimiento de que el contratista había incumplido con su trabajo, ni que el interventor mintió al aprobar el informe de gestión, por esta razón, tanto al director como al tesorero se les debe aplicar el principio de confianza para excluirlos de responsabilidad penal, porque es claro que confiaban en que tanto el contratista como el interventor actuaron legalmente.

Igualmente, desde la figura de la coautoría, ni el director ni el tesorero pueden ser coautores a pesar de participar en el acto complejo de disposición, pues no participaron en el acuerdo común para la realización de la conducta punible. Además, hay que darle aplicación a la teoría de la autoría mediata, según la cual son autores mediatos del delito de peculado el contratista y el interventor, mientras que el director y el tesorero fueron meros instrumentos, y por tanto no responderían por el delito de peculado doloso.

De esta forma, queda claro que no es cierto que todos los que intervienen en el acto de disposición de los recursos públicos sean responsables del delito de peculado, pues de acuerdo con las reglas de la imputación objetiva y subjetiva de un hecho punible es posible encontrar criterios de exclusión de responsabilidad, y evitar los tan perversos efectos de la responsabilidad objetiva y la autoría unitaria, que a veces parecen filtrarse en los pronunciamientos de los órganos jurisdiccionales colombianos.

Ahora bien, para terminar con las diferentes variables del caso, se puede decir que el director y el tesorero podrían responder dolosamente como coautores solo si se prueba que existió acuerdo previo con los demás coautores del delito, pues no basta con afirmar que han debido saber o debieron conocer de los hechos, porque estos argumentos solo podrían fundamentar, si acaso, una responsabilidad culposa del director y el tesorero. Distinto sería si de presentarse un hecho evidente de incumplimiento por parte del contratista, como que este fuera contratado para remodelar el baño público de la entidad, y a pesar de que todos, incluido el director, se pudieron dar cuenta que no inició ninguna obra en el baño, se ordenara el pago por un trabajo que no realizó. Solo en estos eventos el director y el tesorero responderían, cada uno, como autor accesorio de un delito de peculado culposo, pues al no existir acuerdo previo es imposible hablar de coautoría, y solo si se puede romper el principio de confianza y afirmar que no fueron diligentes, $y$ no revisaron la veracidad del informe de gestión del contratista y de la aprobación del interventor, a pesar de que se tenían serios indicios de su incumplimiento y del actuar fraudulento.

Precisamente sobre este punto ha surgido una posición según la cual, el servidor público que 
administra recursos públicos tiene una posición de garante sobre ellos, y por tanto no le es aplicable el principio de confianza. Sobre este particular planteamiento debo exponer mi absoluto rechazo, pues de acuerdo con el principio de buena fe del artículo 83 de la Constitución, y el principio de presunción de inocencia consagrado en el artículo 29 de la Carta, en un juicio penal se debe presumir que el indiciado parte del principio de confianza, y es la Fiscalía la que debe desvirtuarlo. De lo contrario, sería una presunción de culpabilidad y una inversión de la carga de la prueba, figuras que no son aplicables en el derecho penal por prohibición constitucional (art. $29 \mathrm{cN}$ ).

Ahora bien, se deben tener presente dos eventos adicionales, para lo cual utilizaré el mismo caso incluyendo dos variantes. La primera variación consiste en que el director concertó con el contratista y el interventor favorecer al contratista, pero para no verse comprometido con el hecho delegó a un tercero que no es consciente de la situación. En este caso, si el director da la orden a su delegado para aprobar el pago, se convierte en un determinador del peculado si el delegado era consciente del fraude, o en un autor mediato si el delegado no pudo darse cuenta de la maniobra fraudulenta.

En el caso que el director guarde silencio, y el delegado apruebe el pago sin estar enterado del engaño, el interventor y el contratista serían coautores mediatos, y el director sería un cómplice, pues si bien delegó la función en otra persona para facilitar el fraude, permaneció en silencio y no se opuso a la actuación engaño- sa del contratista y del interventor. El delito, en este caso, no se hubiese consumado con las solas acciones $u$ omisiones del director, pues nada habría ocurrido si el contratista no hubiese presentado la cuenta de cobro con el visto bueno del interventor; además, el delegado tuvo toda la posibilidad de estudiar el caso y negar el pago, sin ninguna intervención del director. La solución que propongo es un poco polémica, pero acorde con una imputación en el campo de la acción, donde por regla general es cómplice quien omite o guarda silencio, y los autores son los que dominan el curso causal y son los protagonistas del hecho delictivo.

Por esta razón, en esa línea argumentativa, se considera que a pesar de ser el director, de conocer la maniobra engañosa y de realizar algunos actos dirigidos a facilitarla, no tiene el dominio funcional del hecho como sí lo tienen el contratista y el interventor. Sin embargo, en el mismo supuesto de hecho, existe otra forma de imputación de responsabilidad, que se da a través de la figura de la comisión por omisión contemplada en el artículo 25 del cp. En esta otra forma de imputación se podría argüir que el director, en el caso planteado, tiene el deber y la potestad legal de revocar el acto de delegación, reasumir la función e impedir el fraude, negando el pago que engañosamente había solicitado el contratista. Por esta vía, su conducta se convierte en una comisión por omisión, porque como director de la entidad tiene una posición de garante, en virtud de la cual omitió cumplir con el deber de custodia de los recursos públicos que tiene a su cargo e infringió un deber legal, teniendo la posibilidad y la obligación de impedir dicho resul- 
tado. De este modo, solo a través de la comisión por omisión se podría configurar una posición de garante al director e imputarle un peculado en calidad de coautor.

\section{CONCLUSIONES}

De acuerdo con todo lo antes expuesto se puede concluir que, de conformidad con la estructura de la autoría y la participación consagrada en el cP, en Colombia el funcionario judicial se encuentra obligado por mandato legal a realizar en cada caso concreto la diferenciación entre autores y partícipes (art. 28), utilizando como mínimo los criterios contemplados en el artículo 29, a saber: el acuerdo en común, la división de trabajo y la entidad del aporte. Por esta razón, los órganos jurisdiccionales deben descartar la antigua tendencia de aplicar la teoría de la autoría unitaria, según la cual todo aquel que hiciera un aporte al hecho punible debía ser tenido como autor.

En relación con el delito de peculado debe mencionarse que los criterios de la autoría y la participación se ven afectados por dos elementos especiales que trae la estructura de este tipo penal, como son la calidad de servidor público y la relación funcional que debe existir entre el autor y el bien protegido.

Precisamente, por estas particularidades del delito de peculado es que figuras como el actuar por otro y el interviniente deben ser utilizadas para abordar ciertos casos especiales, donde interviene en el delito un sujeto que no tiene for- malmente la calidad de servidor público, o que no tiene la calidad de servidor público pero es representante legal de una empresa que ejerce una función pública.

En el caso de la relación funcional entre el autor y el bien protegido por el delito de peculado, es claro que solo sería autor aquel funcionario público que tuviese asignada la función, pero como se explicó, esa asignación puede ser de forma directa a través de la ley o un acto administrativo, o a través de un acto de delegación legítimo.

Por último, se deja también sentado que si bien en la función de disponer de recursos públicos deben obligatoriamente participar varias personas dentro de un procedimiento legal, ello no implica, per se, que todos los que participan en este acto complejo deban responder por el delito de peculado en caso de que en determinado trámite se presente una apropiación, pues se requiere constatar todos los elementos de la imputación objetiva y subjetiva del hecho; por esta vía es posible diferenciar entre personas responsables del hecho y personas que deben ser absueltas de toda responsabilidad.

\section{Referencias}

1. Abello Gual, J. A. (Julio-Diciembre de 2010a). El abuso de confianza y el peculado en la responsabilidad penal empresarial: la responsabilidad penal por administración de fondos parafiscales en las E.P.S. en Colombia. Prolegómenos. Derechos y Valores, XIII(28), 267-284. 
2. Abello Gual, J. A. (Enero-Junio de 2010b). El abuso de confianza y el hurto agravado por la confianza en la responsabilidad penal empresarial en Colombia. Prolegómenos. Derechos y Valores, XIII(25), 181-200.

3. Abello Gual. J. A. (2015). Derecho Penal Empresarial. Bogotá: Leyer.

4. Arboleda Vallejo, M. y Ruiz Salazar, J. A. (2013). Manual de Derecho Penal, partes general y especial (Décima ed.). Bogotá: Leyer.

5. Cancino Moreno, A. (1983). El delito de peculado en el nuevo Código Penal: análisis histórico y dogmático. Bogotá: Temis.

6. Corte Suprema de Justicia. Sala Penal. Sentencia 12191 (M. P.: Carlos Eduardo Mejía Escobar; abril 25 de 2002).

7. Corte Suprema de Justicia. Sala Penal. Sentencia 18856 (M. P.: Jorge Aníbal Gómez GaIleo; abril 24 de 2003).

8. Corte Suprema de Justicia. Sala Penal. Sentencia 20704 (M. P.: Carlos Augusto Gálvez Argote; julio 8 de 2003).

9. Corte Suprema de Justicia. Sala Penal. Sentencia 25536 (M. P.: Álvaro Orlando Pérez Pinzón; julio 27 de 2006).

10. Corte Suprema de Justicia. Sala Penal. Proceso 29221 (M. P.: Yesid Ramírez Bastidas; septiembre 2 de 2009).
11. Díaz y García Conlledo, M. (2009). La autoría en el derecho penal. Bogotá: Leyer.

12. Díaz y García Conlledo, M. (1991). La autoría en el derecho penal. Barcelona: PPU.

13. Faraldo Cabana, P. (1996). Delitos societarios. Valencia: Tirant lo Blanch.

14. Fernández Bautista, S. (2007). El administrador de hecho y de derecho. Valencia: Tirant lo Blanch.

15. Fernández Carrasquilla, J. (2012). Derecho penal. Parte general. Teoría del delito y de la pena (Vol. II). Bogotá: Grupo Editorial Ibáñez.

16. Ferre Olive, J. C., Núñez Paz, M. Á. y Ramírez Barbosa, P. A. (2010). Derecho penal colombiano. Parte general: principios fundamentales y sistema. Bogotá: Grupo Editorial lbáñez.

17. Ferreira Delgado, F. J. (2006). Derecho penal especial (t. II). Bogotá: Temis.

18. Figueroa Fonseca, L. C. (2014). El interviniente en el derecho penal. Bogotá: Grupo Editorial Ibáñez.

19. Gómez Méndez, A. y Gómez Pavajeau, C. A. (2008). Delitos contra la administración pública (Tercera ed.). Bogotá: Universidad Externado de Colombia.

20. Jakobs, G. (1998). La imputación objetiva en el derecho penal. Bogotá: Universidad Externado de Colombia. 
21. Jescheck, H.-H., Weigend, T. y Cardenete, M. (2002). Tratado de derecho penal: parte general (Quinta ed.). Granada: Comares.

22. Mir Puig, S. (2010). Derecho penal: parte general (Octava ed.). Barcelona: Reppertor.

23. Molina Arrubla, C. M. (2005). Delitos contra la administración pública. Bogotá: Leyer.

24. Pabón Parra, P. A. (2011). Manual de derecho penal. Parte especial (Octava ed., t. II). Bogotá: Ediciones Doctrina y Ley.

25. Peña Ossa, E. (2005). Delitos contra la administración pública (Segunda ed.) Bogotá: Grupo Editorial Ibáñez.

26. Real Academia Española [rae]. (2001). Administrar. En Diccionario de la lengua española (22. ${ }^{\circ}$ ed.). Recuperado en junio de 2015 de lema.rae: http://lema.rae.es/ drae/?val=administrar.

27. Roso Cañadillas, R. (2002). Autoría y participación imprudente. Granada: Comares.

28. Roxin, C. (2007). Autoría y dominio del hecho en el derecho penal (Séptima ed.). Bar- celona: Marcial Pons, Ediciones Jurídicas y Sociales.

29. Salazar Marín, M. (2011). Autor y partícipe en el injusto penal (Segunda ed.) Bogotá: Grupo Editorial Ibáñez.

30.Schünemann, B. (2007). Aspectos puntuales de la dogmática jurídico penal. Bogotá: Grupo editorial Ibáñez/Universidad Santo Tomás.

31. Suárez Sánchez, A. (2007). Autoría (Tercera ed.). Bogotá: Universidad Externado de Colombia.

32. Tribunal Superior de España. Sentencia de agosto 11 de 2000.

33. Uribe García, S. (2012). Delitos contra la administración pública. Medellín: Ediciones Unaula.

34. Velásquez Velásquez, F. (2013). Manual de derecho penal. Parte general (Quinta ed.). Bogotá: Ediciones Jurídicas Andrés Morales.

35. Velásquez Velásquez, F. (2009). Derecho penal. Parte general (Cuarta ed.). Medellín: Comlibros. 